\title{
SITUAÇÃO ATUAL DA ATIVIDADE TURÍSTICA EM SÃO CRISTOVÃO (SERGIPE, BRASIL)
}

\author{
Current situation of tourism in São Cristovão (Sergipe, Brasil) \\ Situación actual de la actividad turística en São Cristovão (Sergipe, Brasil) \\ Paulo Jobim Campos Mello
Jennifer Daiane M. M. Dantas
}

\section{RESUMO}

A cidade de São Cristóvão, localizada no estado de Sergipe, região Nordeste do Brasil, foi fundada em 1590 e é a quarta cidade mais antiga do país. Possui um patrimônio edificado de enorme relevância, tendo sido tombado pelo Instituto do Patrimônio Histórico Artístico Nacional (IPHAN), em 1967. O conjunto arquitetônico da Praça São Francisco, seu principal monumento, foi tombado pela UNESCO, em agosto de 2010, como Patrimônio Cultural da Humanidade. No entanto, mesmo passados mais de dois anos da elevação da Praça de São Francisco a patrimônio cultural da humanidade, parece que o processo de turistificação ainda não ocorreu na cidade. $\mathrm{O}$ presente trabalho pesquisa junto aos turistas que chegam à cidade qual a percepção que tem do patrimônio histórico, bem como da infraestrutura turística oferecida.

Palavras-chave: Patrimônio Cultural; Turismo Cultural; Cidade de São Cristóvão

\section{ABSTRACT}

The city of São Cristóvão, in the state of Sergipe, northeastern Brazil, was founded in 1590 and is the fourth oldest city in the country. It has a built heritage of great importance, having been listed by the National Historical and Artistic Heritage (IPHAN) in 1967. The architectural ensemble of the Plaza San Francisco was listed by UNESCO in August 2010 as a World Heritage Site. However, even after more than two years, it seems that the development of tourism activities has not yet occurred in the city. This paper survey the perception of historical heritage by the tourists that arriving in the city as well as the tourism infrastructure offered.

Keywords: Cultural Heritage, Cultural Tourism, City of São Cristóvão

\section{RESUMEN}

La ciudad de São Cristóvão, en el estado de Sergipe, noreste de Brasil, fue fundada en 1590 y es la cuarta ciudad más antigua del país. Tiene un patrimonio histórico y cultural de gran importancia, después de haber sido incluido por el Patrimonio Histórico y Artístico Nacional (IPHAN), en 1967. La Plaza San Francisco, su principal conjunto arquitectónico, fue incluida por la UNESCO, en agosto de 2010, como Patrimonio de la Humanidad. Incluso después de la Plaza San Francisco se ha vuelto patrimonio cultural de la humanidad, parece que el proceso de turistificación todavía aún no se ha sucedido en la ciudad. Este trabajo de investigación se lleva a cabo con los residentes de São Cristóvão, a percibir su identificación

\footnotetext{
${ }^{1}$ Professor do Departamento de Arqueologia da Universidade Federal de Sergipe - paulojc.mello@gmail.com

${ }^{2}$ Bacharelado em arqueologia pela Universidade Federal de Sergipe -jenniferarqueologa@ yahoo.com.br
} 
con la Plaza San Francisco, y su identificación con el turismo. La investigación también se llevó a cabo con los turistas que acuden a la ciudad para ver lo que piensan del patrimonio histórico de la ciudad y de la infraestructura turística que ofrece.

Palabras clave: Patrimonio Cultural; Turismo; ciudad de São Cristóvão

\section{Introdução}

A região nordeste do Brasil é conhecida por suas belas praias e pela presença do sol na maior parte do ano, atraindo grande número de turistas, não só nacionais, mas também de origem estrangeira. Sergipe, o menor estado da federação, localizado nessa mesma região, tem como ponto forte na atração turística suas praias, além de outros passeios ecológicos, principalmente, pelos rios e serras existentes no estado.

É inegável o crescimento das atividades turísticas em todo o mundo. Dentre as modalidades de turismo, aquele denominado cultural, que pode ser definido como "a prática turística que envolva a apreciação ou a vivência de qualquer tipo de manifestação cultural, seja tangível ou intangível, mesmo que não seja a atividade principal praticada pelo viajante no destino" (DIAS, 2006: 40), aparece como uma das estratégias de desenvolvimento sustentável $^{3}$, na medida em que há preocupação em aliar desenvolvimento econômico com a melhoria da qualidade de vida, saúde, emprego, segurança, preservação do patrimônio e do meio ambiente, bem como o respeito à diversidade. Assim, o turismo cultural pode apresentar-se tanto como um caminho para a obtenção de fundos necessários à preservação da herança cultural, como uma ferramenta para proporcionar o desenvolvimento econômico local e regional.

Mesmo na modalidade de turismo cultural, o estado de Sergipe tem muito a oferecer, sendo que dois de seus conjuntos urbanos são protegidos pelo Instituto do Patrimônio Artístico Histórico Nacional (IPHAN): Laranjeiras, não só por seu conjunto arquitetônico (tombado como patrimônio estadual, desde 1971, e federal, desde 1993), mas por todas as festas populares que ali acontecem; e São Cristóvão, que teve a Praça de São Francisco tombada pela UNESCO, em agosto de 2010, como Patrimônio Cultural da Humanidade (sendo que o conjunto urbanístico da cidade já havia sido tombado como patrimônio estadual desde 1938, e federal desde 1967).

\footnotetext{
${ }^{3}$ Para uma discussão sobre sustentabilidade e desenvolvimento sustentável nas atividades turísticas, ver Alfonso (2012: 26 ss).
} 
Pretendemos, no presente trabalho, focar nossos estudos no aproveitamento turístico da cidade de São Cristóvão, uma vez que ela abriga, como já foi dito, um dos poucos patrimônios brasileiros eleitos como patrimônio da humanidade.

\section{A cidade de São Cristóvão}

A cidade de São Cristóvão conta, atualmente, com uma população de 78.864 habitantes, sendo que seu núcleo urbano está localizado há $26 \mathrm{~km}$ da capital, Aracaju, que é a maior cidade e principal porta de entrada do estado. Seu índice de Desenvolvimento Humano (IDH), em 2010, era de 0,662, o segundo maior do estado, mas que a colocava somente em $2.864^{\circ}$ lugar entre as 5564 cidades brasileiras. Se levássemos em conta apenas o componente 'renda' (IDH renda = 0,624), sua colocação, dentro do estado, cairia para quarto lugar e, a nível nacional, para $3260^{\circ}$. Não há dúvida, portanto, que o incremento do turismo ajudaria em muito no desenvolvimento da cidade.

Apesar de São Cristóvão não contar com praias, seu patrimônio cultural ${ }^{4}$ é de tal relevância que, sem dúvida, atrairia uma grande quantidade de turistas. Na verdade, como pode ser visto em Cohen (1979), não existe um único tipo de turismo (ou de turista), sendo que o referido autor distingue cinco categorias de experiências turísticas: recreativo, diversionista, experiencial, experimental e existencial, com esses tipos variando de acordo com o objetivo que a experiência tem para o turista dentro do contexto de sua atitude geral para a sociedade e o mundo a sua volta. Acreditamos que mesmo para o recreativo, em que a viagem não é nada além da recreação através do qual o turista se recupera das tensões do seu dia-a-dia, aqueles interessados primordialmente nesse turismo de 'sol e praia', não se furtariam a apreciar, também, as belezas culturais da região (BARRETO, 2007, entre outros), principalmente pela proximidade entre Aracaju e São Cristóvão.

Sendo a $4^{\mathrm{a}}$ cidade mais antiga do Brasil, São Cristóvão foi fundada em 1590, por Cristóvão de Barros. O povoado, no início século XVII, teve sua localização modificada por diversas vezes, até ser definitivamente estabelecida às margens do rio Paramopama, afluente do Vaza-Barris. Ainda durante o século XVII, ficou sob ocupação holandesa de 1637 a 1645, sendo inteiramente reconstruída após o conflito. No início do século XVIII foi retomada da

\footnotetext{
${ }^{4}$ Patrimônio cultural pode ser definido como o corpus de signos materiais transmitido do passado para cada cultura e, então, para a humanidade inteira. A ideia de patrimônio foi ampliada para incluir o patrimônio imaterial, abrangendo os sinais e os símbolos passados por transmissão oral, as formas de expressão artística e literária, linguagens, modos de vida, mitos, crenças e rituais, sistemas de valores e conhecimentos tradicionais (JOKILETHO, 2005).
} 
província da Bahia, e tornou-se sede da capital de Sergipe de 1823 até 1855 quando o governo foi transferido para Aracaju (IBGE, 2009).

A parte alta da cidade ainda conserva inúmeras construções de interesse arquitetônico, tendo sido tombada pelo Decreto-lei $\mathrm{n}^{\circ} 94$ de 22 de junho de 1938, o qual transformou a cidade em patrimônio histórico de interesse Estadual, e mais tarde, em 1967, foi feito pelo IPHAN um tombamento a nível Federal.

Além dos casarios e igrejas (Matriz de Nossa Senhora da Vitória, do Carmo, Nossa Senhora do Rosário dos Homens Pretos), seu principal conjunto arquitetônico está localizado na Praça São Francisco, tombada pela UNESCO em 2010, como já foi mencionado, como patrimônio da Humanidade.

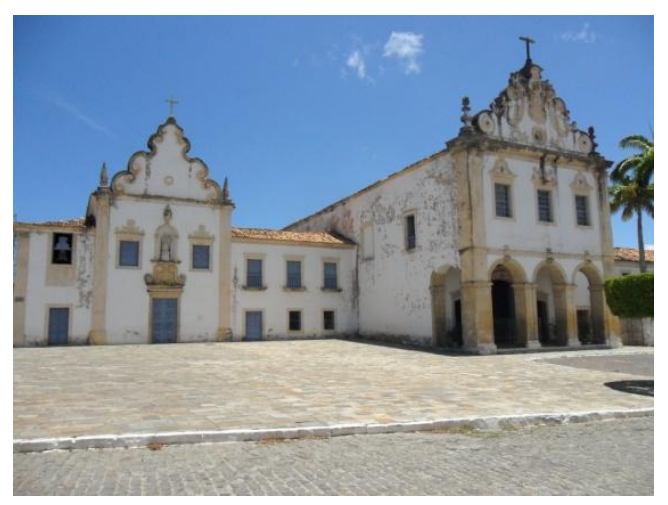

Foto 1: Foto 1 - Igreja e Convento do Carmo.

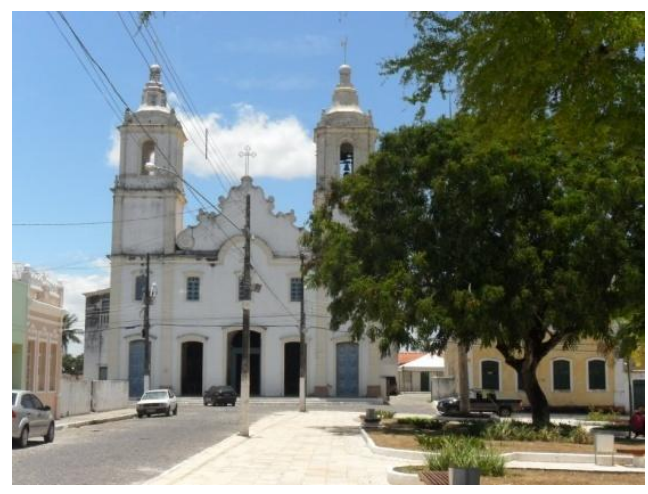

Foto 2: Igreja Matriz.

A praça foi apresentada como um exemplo material único do momento histórico em que Portugal e Espanha encontravam-se unidos sob uma única coroa, período denominado de União Ibérica (1580-1640).

Como modelo baseado no código filipino de urbanização, a Praça São Francisco possui o espaço quadrado, com suas relações de comprimento e largura ajustadas ao preconizado na Lei IX das Ordenações. Bem como as quatro vias secundárias e principais 
desaguando nos quatro vértices, onde em tudo relembra o que se recomendava para a Praça Maior de uma cidade. Diferentemente dos outros modelos franciscanos edificados no nordeste do Brasil - que têm à frente uma rua ou espaço menor, - o Conjunto Arquitetônico da Praça São Francisco possui, à sua frente, espaço amplo cercado por outros edifícios coloniais (ARAGÃO, 2011: 100).

Em volta da praça encontramos a Igreja de São Francisco (fundada em 1567), o Convento de Santa Cruz, a Capela da Ordem Terceira, onde funciona o atual Museu de Arte Sacra; a antiga Santa Casa com a Igreja da Misericórdia (que foi também o Hospital de Caridade e, atualmente, é o Lar Imaculada Conceição, onde também funciona uma pousada), e o Palácio dos Governadores, construção do final do século XVIII (onde, desde 1960, funciona o Museu Histórico de Sergipe).

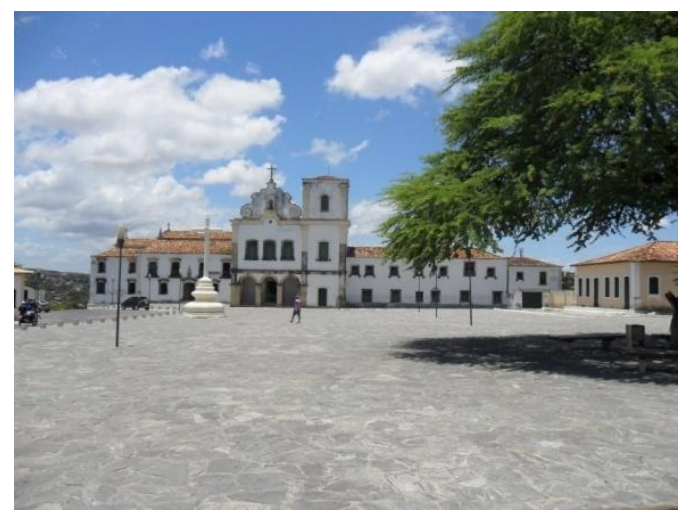

Foto 3: Igreja e Convento de São Francisco.

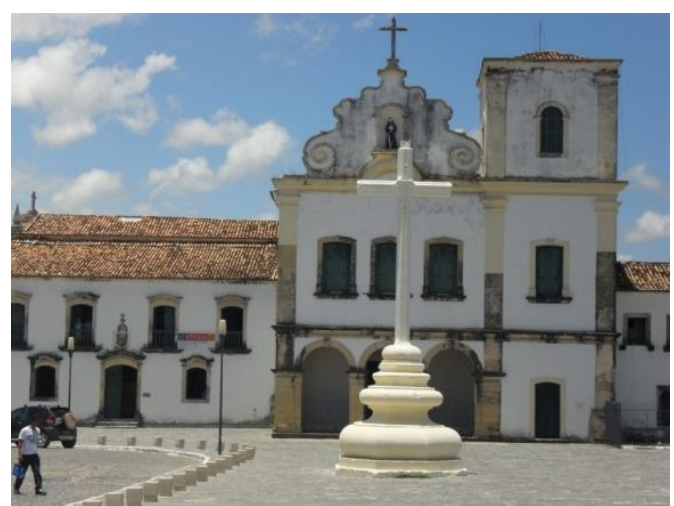

Foto 4: Detalhe do Cruzeiro, comum nos conjuntos franciscanos. 


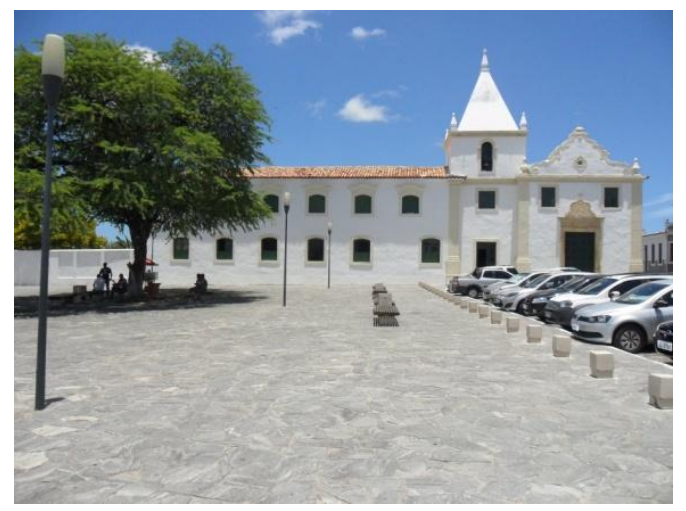

Foto 5: Antiga Santa casa e Igreja de Misericórdia.

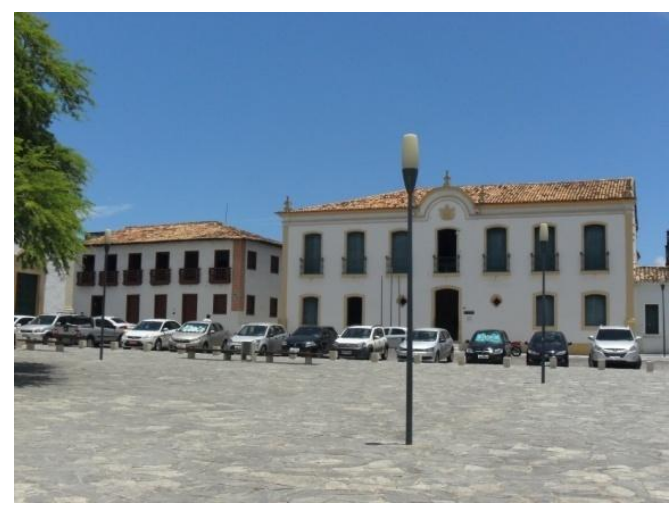

Foto 6: Palácio dos Governadores.

A elevação da Praça São Francisco à Patrimônio da Humanidade foi uma vitória de valor incalculável para a população de Sergipe, em geral, e a de São Cristóvão, de maneira particular. Com a autoestima aflorada, o povo sergipano terá de forma mútua a oportunidade de buscar o avivamento de suas raízes histórico-culturais, garantindo suas memórias para que as futuras gerações também possam conhecer e apropriar-se delas.

Outro benefício provável para a região será o crescimento econômico, através do aquecimento da economia motivada pelo comércio em geral, inclusive de artesanato e comidas típicas que virá junto ao maior fluxo turístico (grifo nosso) (SANTOS et al., 2010/2011: 73).

Ainda de acordo com os mesmos autores, a cidade não estaria preparada, em termos de infraestrutura, para receber esse maior número de visitantes e teria que se preparar rapidamente para isso:

No referente à questão da infra-estrutura da cidade, sabemos que ainda é muito precária, a falta de restaurantes, hotéis, pousadas, drogarias, bons serviços de bar e de transporte, são exemplos dessa deficiência. O problema é bastante significativo, necessitando de urgência, pois a cidade que recebia uma quantidade pequena de visitantes ganhou projeção internacional (SANTOS et al., 2010/2011: 73). 
É isso que pretendemos discutir no próximo item: a cidade de São Cristóvão vem recebendo um número de turistas compatível com a sua importância? A cidade preparou-se, em termos de infraestrutura, para receber esses visitantes?

\section{Quem vai à São Cristóvão e qual a percepção do visitante}

Para termos uma ideia sobre qual a porcentagem de turistas que, chegando ao Estado de Sergipe, visitam São Cristóvão, e qual a opinião deles sobre a cidade, foi elaborado e distribuído um questionário em três hotéis, de categorias diferentes, na cidade de Aracaju, que é a porta de entrada do estado.

A primeira parte do questionário era sobre os dados pessoais do turista: sua origem (estado e cidade); motivo da viagem (passeio, trabalho, outros); companhia durante a viagem (família, amigos, nenhuma); sexo e faixa etária. A segunda parte listava as opções turísticas existentes no Estado e oferecidas pela maioria das agências de viagens: pedia-se ao turista que marcasse os passeios realizados, indicando a ordem de preferência. Por fim, a última parte versava exclusivamente sobre a cidade de São Cristóvão, listando não só os pontos turísticos, mas também a infraestrutura oferecida pela cidade (condições da estrada de acesso, guias turísticos, bares, restaurantes, etc), e pedia ao turista que desse notas (de 1 a 10, sendo 10 quando considerasse o serviço e/ou ponto turístico excelente) para aquelas que utilizou ou visitou; perguntava-se, ainda, se o turista tinha ido à cidade por conta própria ou por meio de uma agência de turismo e, por fim, havia um espaço para comentários.

Tivemos um total de 38 questionários respondidos.

Quanto à origem dos turistas pudemos perceber que eles vieram de oito estados diferentes: Minas Gerais (8), Rio de Janeiro (7), Bahia (6), São Paulo (5), Mato Grosso do Sul (4), Pernambuco (3), Distrito Federal (2) e de cidades do interior de Sergipe (2), além de um turista que respondeu de forma inelegível esta questão. É possível perceber que, enquanto a grande maioria $(52,6 \%)$ dos turistas vem da região sudeste (São Paulo, Rio de Janeiro e Minas Gerais), nenhum veio das regiões Sul ou Norte.

A grande maioria (34) estava a passeio, enquanto apenas quatro vieram a trabalho. A viagem com a família também foi a opção da maioria, conforme pode ser visto no gráfico abaixo: 
Gráfico 1 - Companhia durante a viagem.

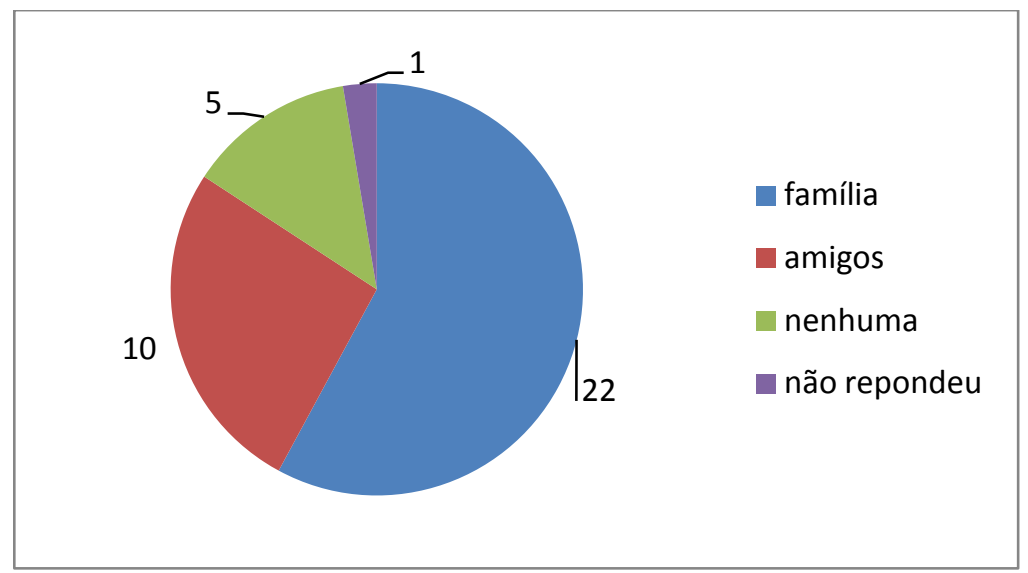

Em relação à faixa etária, temos que a maioria dos turistas $(26$, ou $68,4 \%)$ se encontra entre 31 e 60 anos:

Gráfico 2 - Faixa etária.

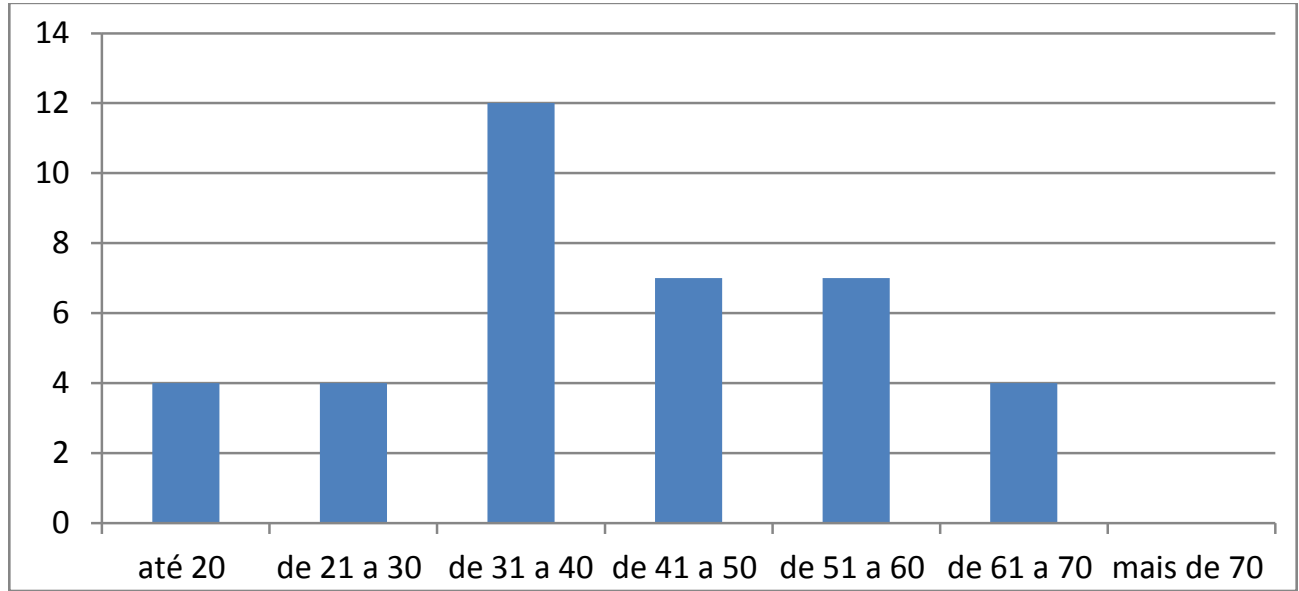

Com respeito às opções turísticas visitadas, é possível notar que apenas cinco turistas (13,2\% do total) foram até São Cristóvão, demonstrando a baixa frequência de visitação da cidade (o mesmo ocorreu com outra importante cidade histórica do estado: a cidade de Laranjeiras foi visitada por apenas 3 turistas, ou seja, 7,9\% do total).

Os passeios mais procurados foram os de Xingó (24 turistas, ou 63,2\%) e Mangue Seco (16 turistas, ou 42,1 \%). Em Xingó, a principal atração é o passeio pelos cânions do rio São Francisco (além de haver várias outras opções, como a Rota do Cangaço, a Usina Hidrelétrica de Xingó, etc), enquanto que Mangue Seco é uma conhecida praia, já do lado baiano mas cujo acesso é muito mais próximo e fácil de ser feito através de Aracaju do que de Salvador. 
Gráfico 3 - Passeios realizados pelos turistas.

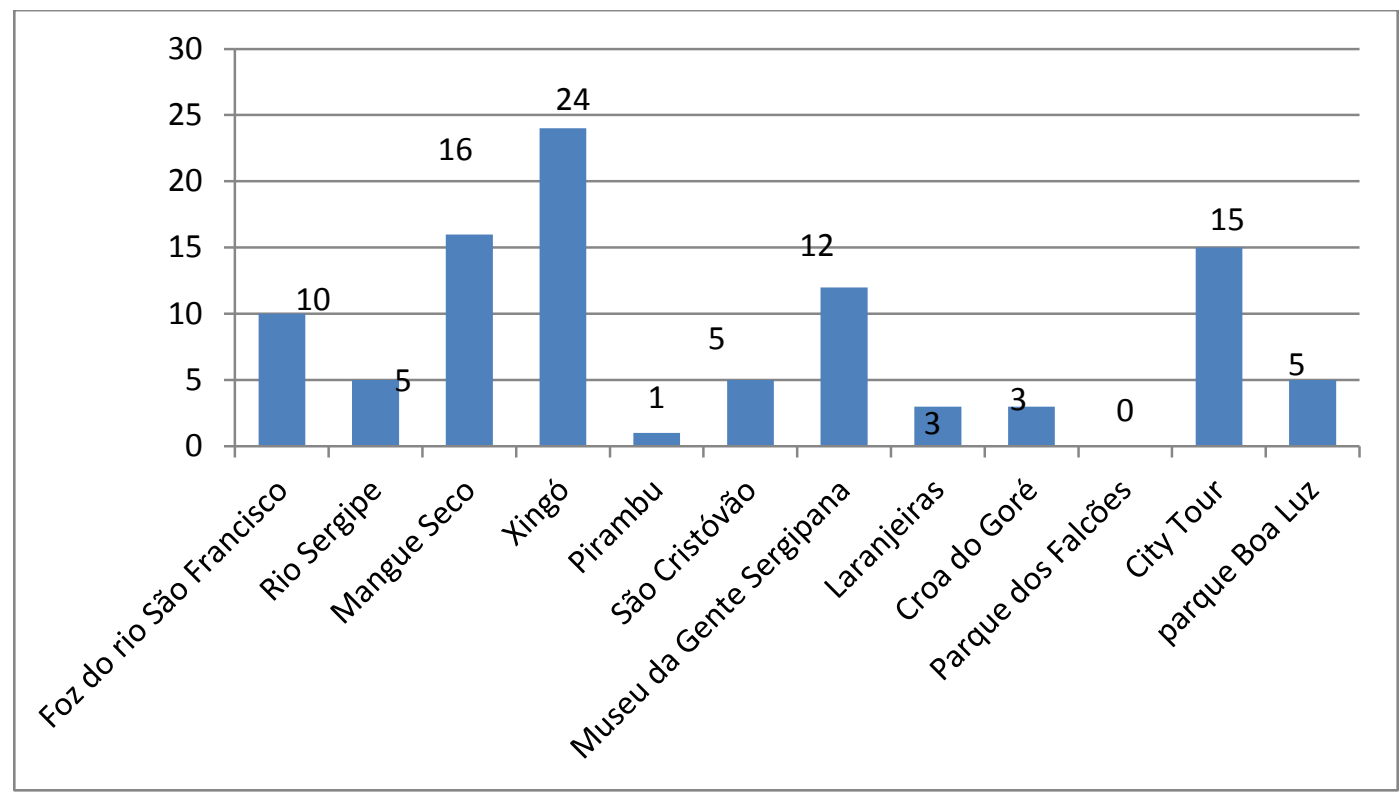

Apenas três, dos cinco turistas que visitaram a cidade de São Cristóvão, responderam corretamente a questão que pedia que informassem que lugar de preferência esse passeio ficou em relação aos outros realizados: um colocou a visita à São Cristóvão em terceiro lugar, dentre os três passeios realizados por ele (ficando atrás de Mangue Seco e do City Tour); outro, colocou em segundo lugar dentre os três realizados (ficou atrás da visita ao Museu da Gente Sergipana e na frente do passeio pelo rio Sergipe), e, por fim, outro, colocou em $6^{\circ}$ lugar entre os sete pontos visitados (ficando a frente apenas da visita feita à cidade de laranjeiras, e atrás de Mangue Seco, da Foz do Rio São Francisco, de Xingó, do Museu da Gente Sergipana e do Parque Boa Luz). Ou seja, os turistas que se deslocaram até São Cristóvão não se impressionaram muito com o passeio e com o que viram por lá; mas é possível perceber, também, que os passeios 'ecológicos' levam grande vantagem sobre os 'culturais'.

Em relação à visita feita à São Cristóvão, quatro foram até lá por conta própria (o outro não respondeu a essa questão), o que pode demonstrar a completa falta de interesse das agências de turismo em levar as pessoas à cidade.

Com respeito à opinião dos turistas sobre a infraestrutura oferecida na cidade e aos pontos turísticos lá existentes, pudemos aproveitar quatro dos cinco questionários. A estrada de acesso à cidade recebeu as seguintes notas: 6, 6, 7 e 8; as informações turísticas (mapas, folders, placas e etc): 3, 5 e 6; os guias turísticos, 1, 8 e 10; locais para compras de lembranças e artesanatos, apenas uma nota: 10, o mesmo acontecendo com bares e restaurantes: 1 . 
O 'aspecto geral da cidade' mereceu as seguintes notas: 7, 8, 8 e 10, um pouco acima ao ‘estado de conservação’: 7, 7, 8, e 8 .

Já os pontos turísticos obtiveram as melhores notas. A Praça de São Francisco mereceu três notas 10; a Igreja e Convento de São Francisco: 9 e 10, mesmas notas obtidas pela Igreja Matriz. O Museu de Arte Sacra recebeu 8 e 10, enquanto o Museu Histórico apenas uma nota: 10

Apesar dos pontos turísticos receberem notas altas, percebe-se que as notas para a infraestrutura oferecida pela cidade são baixas, principalmente para os quesitos 'informações turísticas' e 'bares/restaurantes'. Ou seja, os turistas parecem gostar do patrimônio histórico que encontram em São Cristóvão, porém as condições oferecidas pela cidade para um bom aproveitamento, por parte do turista, deixam muito a desejar.

Para finalizar, três turistas fizeram comentários: um deles elogioso à cidade como um todo, ao guia local e aos museus; outro, apesar de elogiar a cidade 'uma verdadeira volta ao passado', e os guias de rua, que 'foram de suma importância', lamentava a falta de apoio a esses guias, e também 'a falta de restaurantes e atividades na cidade, além de pouquíssima divulgação da mesma'. Já o último foi uma reclamação, dizendo que não pode visitar nada, pois 'era $2^{\text {a }}$ feira e tudo estava fechado!'.

Podemos ter uma ideia do fluxo turístico na cidade de São Cristóvão também através dos dados disponíveis no blog do Museu Histórico, um dos mais importantes da cidade, localizado na Praça São Francisco.

Quanto ao número de visitantes, temos os seguintes dados:

Gráfico 4 - Fluxo de visitantes do Museu Histórico, 2005 a 2012, fonte: Museu Histórico de São Cristóvão

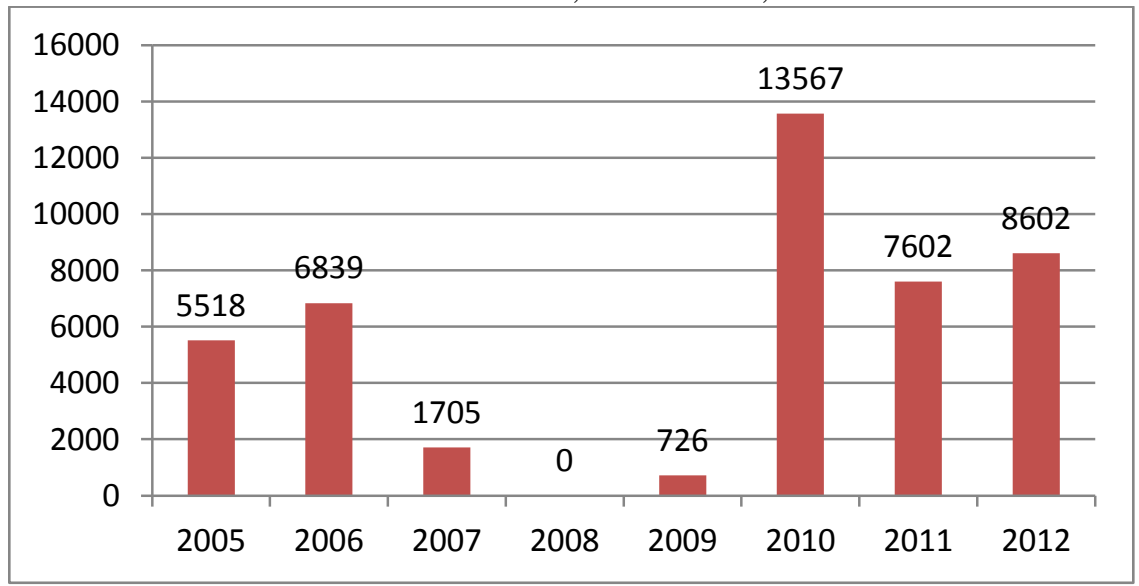

Pelo gráfico acima, é possível perceber que o auge da visitação do Museu se deu no ano de 2010, quando a campanha para que a Praça se tornasse Patrimônio da Humanidade 
também se encontrava no seu apogeu. A instituição foi fechada, para restauração do prédio, de abril de 2007 a novembro de 2009, causa da baixa visitação nesse período, como também é possível perceber no gráfico.

Se levarmos em conta somente os anos de 2005, 2006, 2011 e 2012, desconsiderando os outros que foram atípicos, é possível notar um crescimento no número de visitações feitas ao museu, conforme é destacado pelo próprio site.

Outros dados disponibilizados são referentes principalmente ao ano de 2012. Nesse ano, como já foi visto, o museu foi visitado por 8602 pessoas, sendo que podemos dividi-las em dois grupos: excursões escolares, que contaram com a presença de 4095 alunos (47,6\%) e turistas propriamente ditos, 4507 (52,4\%), sendo estes últimos oriundos de todos os estados da federação (exceção feita ao estado do Acre, de onde não veio nenhum turista).

Em relação aos turistas, que são o foco principal de nosso estudo, 1784 (43,6\%) são originários do próprio estado de Sergipe. São Paulo, com 412 visitantes (9,1\%), Rio de Janeiro, com 309 (6,9\%), e Bahia, com 263 (6,4\%) são os estados que mais enviaram turistas para a visitação do museu.

Também os dados nos informam a presença de turistas vindos do exterior: foram 74 estrangeiros (o que representa 1,8\% do total), vindos de 16 diferentes países: Alemanha (8), Angola (2), Argentina (5), Canadá (4), Bélgica (2), Chile (2), Espanha (2), Estados Unidos (11), França (12), Holanda (1), Inglaterra (7), Itália (6), México (1), Peru (3), Portugal (7) e Suíça (1).

Esses números mostram baixa taxa de visitação. Levando-se em conta que o horário de funcionamento do museu é de terça-feira a domingo, ou seja, 6 dias por semana, temos, aproximadamente, um total de 300 dias úteis anuais de funcionamento, o que daria uma média um pouco maior de 15 visitantes por dia; se levarmos em conta apenas os visitantes vindos de outros estados, essa média cai para pouco mais de 9 visitantes por dia.

\section{A perspectiva dos moradores e dos trabalhadores da área de cultura de São Cristóvão}

Também conseguimos informações através da aplicação de entrevistas a dois grupos distintos: 1) moradores de São Cristóvão, e 2) pessoas que trabalham na área de turismo cultural (em museus, guias de turismo, etc.) em São Cristóvão. Em ambos os grupos tivemos o intuito de perceber seu conhecimento sobre patrimônio cultural e arqueológico ${ }^{5}$, sobre as

\footnotetext{
${ }^{5} \mathrm{O}$ patrimônio arqueológico pode ser definido como sendo a parte do patrimônio material em respeito aos quais os métodos arqueológicos proporcionam as informações primárias. Compreende todos os vestígios da existência
} 
condições da cidade em receber turistas, além da percepção deles sobre a Praça São Francisco.

Foram entrevistados onze moradores, cujo perfil pode ser visto no quadro a seguir:

Quadro 1 - Perfil dos Moradores que Participaram da Pesquisa

\begin{tabular}{lllll}
\hline Sujeito & Sexo & Idade & Tempo na Cidade & Grau de Instrução \\
\hline 01 & Feminino & 43 anos & 23 anos & Nível médio completo \\
02 & Feminino & 36 anos & 36 anos & Nível médio completo \\
03 & Feminino & 34 anos & 34 anos & Nível médio completo \\
04 & Masculino & 31 anos & 31 anos & Superior completo \\
05 & Feminino & 48 anos & 48 anos & Nível médio completo \\
06 & Feminino & 19 anos & 18 anos & Superior completo \\
07 & Masculino & 53 anos & 53 anos & Pós-graduado \\
08 & Feminino & 54 anos & 54 anos & Nível médio completo \\
09 & Feminino & 24 anos & 24 anos & Nível médio completo \\
10 & Feminino & 42 anos & 22 anos & Nível médio completo \\
11 & Feminino & 61 anos & 61 anos & Nível médio completo
\end{tabular}

Quanto ao conhecimento sobre patrimônio cultural e arqueológico, dez dos onze moradores entrevistados já ouviram falar sobre patrimônio cultural; oito sabem o que é patrimônio arqueológico (os três restantes nunca ouviram falar de tal tema). Seis moradores nunca ouviram falar da existência de patrimônio arqueológico em São Cristovão, três afirmaram ter ciência da existência desse tipo de patrimônio na cidade, e dois responderam que não conheciam, mas já ouviram falar.

Oito moradores disseram não saber se a cidade está preparada para receber visitas/turistas, enquanto os três restantes afirmaram que a cidade possui estrutura suficiente.

Já em relação à Praça São Francisco, dez moradores têm boas lembranças da Praça, enquanto um afirmou ser indiferente à sua existência. Para nove entrevistados, a Praça São Francisco é muito importante, enquanto que para um, ela é pouco importante, e para o outro ela não tem importância nenhuma. 
Nove moradores sabem que a Praça São Francisco foi elevada a patrimônio mundial, sendo que seis deles afirmaram que, de alguma forma, tiveram participação nesse processo de elevação.

Seis moradores perceberam mudanças no fluxo de turistas na cidade depois da elevação da Praça a patrimônio mundial, três não souberam dizer se houve ou não mudança, enquanto que para dois deles não mudou nada.

Para sete moradores nada mudou em suas vidas depois da elevação da Praça São Francisco a patrimônio mundial; para três aconteceram algumas mudanças, e um não soube dizer.

Foram entrevistados nove trabalhadores da área cultural, cujo perfil pode ser visto no quadro a seguir:

Quadro 2 - Perfil dos Trabalhadores que Participaram da Pesquisa

\begin{tabular}{|c|c|c|c|c|c|}
\hline Sujeito & Sexo & Idade & $\begin{array}{c}\text { Tempo na } \\
\text { Cidade }\end{array}$ & Ocupação & Grau de Instrução \\
\hline 1 & Feminino & 19 anos & 19 anos & Estagiaria & Superior Incompleto \\
\hline 2 & Feminino & 21 anos & 21 anos & Estagiaria & Superior Incompleto \\
\hline 3 & Masculino & 39 anos & 39 anos & $\begin{array}{l}\text { Funcionário } \\
\text { MHS }\end{array}$ & Pós graduado \\
\hline 4 & Feminino & 24 anos & 24 anos & Estagiaria & Superior Incompleto \\
\hline 5 & Masculino & 35 anos & 35 anos & Guia turístico & Superior \\
\hline 6 & Masculino & 20 anos & - & Mediador & Superior Incompleto \\
\hline 7 & Feminino & 19 anos & 02 anos & Estagiaria & Ensino médio \\
\hline 8 & Masculino & 47 anos & - & Artesão & Superior \\
\hline 9 & Feminino & 49 anos & 49 anos & Prof $^{a}$ História & Superior \\
\hline
\end{tabular}


Quanto à compreensão sobre o patrimônio cultural e arqueológico, oito entrevistados responderam que o sítio arqueológico 'representa o passado de um povo', e um que ele 'pode ajudar a comunidade'; ninguém respondeu 'problema' e 'nada'.

Os mesmos oito responderam que o turismo gera oportunidades de emprego, enquanto um não soube responder; a resposta 'não gera nada' não foi marcada por ninguém.

Sete responderam que São Cristovão não tem estrutura para o desenvolvimento da atividade turística; um marcou a resposta 'sim', que tem, e outro não soube responder.

Oito entrevistados indicaram que a elevação da Praça São Francisco à Patrimônio da Humanidade representou um aumento de oportunidades para a cidade, enquanto um mostrou indiferença e a resposta 'ameaça' não foi escolhida por ninguém. Os mesmos oito afirmaram que houve um aumento no fluxo de turistas, enquanto que um não soube dizer se houve ou não.

Para todos os entrevistados existe a necessidade de novos projetos focados no turismo

\section{Considerações finais}

Está claro para vários autores (BARRETO, 2007; YI-DE \&CHI-FAN, 2011, ente outros) que uma das partes mais vantajosas de turismo cultural é seu uso como um veículo para o desenvolvimento econômico ou para a regeneração de locais que se encontravam abandonados.

Está claro, também, que a cidade de São Cristóvão possui um patrimônio cultural digno de ser visitado e apreciado, tanto que parte dele se tornou Patrimônio da Humanidade. Porém, só esse fato não é suficiente para que os turistas afluam ao local, como pode ser visto pelo fluxo de turistas na cidade.

Depois de dois anos da Praça de São Francisco ter sido elevada a Patrimônio da Humanidade, o processo de turistificação ainda não se instaurou na cidade. Toda a esperança de um aumento no afluxo de turistas, tanto nacionais como internacionais, não se concretizou. Quem vai visitar um local que apresente infraestrutura precária, como estrada de acesso mal conservada, sem qualquer tipo de informação sobre o patrimônio (sejam placas de sinalização, sejam folders e/ou mapas) sem contar as questões mais básicas, como bares, restaurantes, lojas de souvenires, ou qualquer outra forma de lazer; pior, quem vai levar os turistas até lá? 
Como pudemos ver em nossa pequena amostra, os poucos turistas que foram até lá, foram por conta própria.

Não há um marketing junto às operadoras de turismo para que se aumente a frequência de turistas na cidade. Pelo contrário, há até uma propaganda contra: conforme conversa informal com um funcionário de hotel, o mesmo confidenciou que não indica mais o passeio aos turistas, pois havia muita reclamação, por parte deles, sobre a falta de opções na cidade.

Foram veiculadas pela imprensa, nos últimos meses, várias notícias sobre o investimento do governo federal na preservação do patrimônio histórico no estado de Sergipe (ver sites governo-br; projeto monumenta; infonet). Acreditamos que a questão não seja simplesmente essa; como foi visto pelos questionários respondidos, o principal problema encontra-se na infraestrutura da cidade, não nos monumentos.

Acreditamos, ainda, que há falta de envolvimento da população com essa questão turística; apesar de ela já estar informada da necessidade de preservação desse patrimônio, ainda não tomou consciência dos benefícios (ou problemas!) que o desenvolvimento turístico pode trazer para toda a comunidade.

\section{Referências bibliográficas}

ALFONSO, Louise Prado. Arqueologia e Turismo: sustentabilidade e inclusão social. Tese de Doutorado apresentada ao Museu de Arqueologia e Antropologia da Universidade de São Paulo. São Paulo, 2012.

ARAGÃO, Ivan Rego. "Praça São Francisco em São Cristóvão-Sergipe-Brasil: lócus sociocultural e patrimônio da humanidade". Revista Eletrônica do Programa de PósGraduação em Museologia e Patrimônio - PPG-PMUS Unirio, vol. 4, n. 2. p. 97-109, 2011.

BARRETTO, Margarita. Cultura e turismo: discussões contemporâneas. Campinas: Papirus, 2007.

COHEN, Erik. "Rethinking the sociology of tourism". Annals of tourism research. v. 6, n. 1. p. 18-35, 1979.

DIAS, Reinaldo. Turismo e patrimônio cultural. São Paulo: Saraiva, 2006.

JOKILETHO, Jukka. Definition of cultural heritage. 2005. Disponível em: http://cif.icomos.org/pdf_docs/Documents\%20on\%20line/Heritage\%20definitions.pdf.

SANTOS, C. M; OLIVEIRA, M. R. \& CAMPOS, P. R. S. "Na praça São Francisco (São Francisco -SE) e o devir de um patrimônio da humanidade". Candeeiro - ADUFS, vols. 19 e 20. p. $71-75,2010 / 2011$. 
YI-DE Liu \& CHI-FAN Lin. "The Development of Cultural Tourism: A Review of UK Experience". Tourismos. v. 6, n. 2. p. 363-376, 2011.

http://www.governo-br.com/governo-ja-investiu-r-37-mi-na-preservacao-do-patrimoniohistorico-de-se/ - Governo já investiu R \$ 37 mi na preservação do patrimônio histórico de SE. Acesso em 14 de fevereiro de 2013.

http://www.infonet.com.br/cidade/ler.asp?id=140065\&pagina=1 - São Cristóvão debate Plano para as Cidades Históricas. Acesso em 14 de fevereiro de 2013.

http://www.monumenta.gov.br/site/?p=6050 - São Cristóvão - SE recebe monumentos restaurados. Acesso em 14 de fevereiro de 2013. 